\title{
Rethinking passive transport: Bus fare exemptions and young people's health
}

\author{
Alasdair Jones, ${ }^{1}$ Rebecca Steinbach, ${ }^{1}$ Helen Roberts, ${ }^{2}$ Anna Goodman ${ }^{1}$ and Judith Green ${ }^{1}$ \\ $1 \quad$ London School of Hygiene \& Tropical Medicine \\ $2 \quad$ UCL Institute of Child Health
}

Corresponding author: Judith Green, London School of Hygiene \& Tropical Medicine, Keppel Street, London, WC1E 7HT, UK (judith.green@1shtm.ac.uk).

Note: this is a personal version, created by Anna Goodman, of the text of the accepted journal article. It reflects all changes made in the peer review process, but does not incorporate any minor modifications made at the proof stage. The complete citation for the final journal article is:

- Jones A, Steinbach R, Roberts H, Goodman A, Green J. Rethinking passive transport: Bus fare exemptions and young people's health. Health and Place. 2012;18 (3):605-612

- DOI: 10.1016/j.healthplace.2012.01.003

Copyright (C) and Moral Rights for this paper are retained by the individual authors and/or other copyright owners 


\begin{abstract}
$\underline{\text { Abstract }}$
Much recent public health research has emphasised the health impacts for young people of 'active travel' modes, typically defined as walking and cycling. Less research has focused on public transport modes. Drawing on qualitative data we examine the links between bus travel and health in London, where young people currently have free bus travel. Our findings indicate that bus travel can be both a physically and socially active experience for young people. We suggest a more nuanced understanding of 'active travel' is now needed, alongside greater attention to urban public transport networks as key sites for health-related travel behaviour.
\end{abstract}

Keywords: Active transport; young people; public transport; qualitative research; public health

\title{
Highlights
}

- Young people aged 12-18 in London have had free bus travel since 2005/6.

- This removes any financial incentive to walk, but also generates additional trips.

- Transport poverty is not a significant issue for young people in London.

- Buses provide a key site for sociability and public engagement in the city.

- Our findings problematise the assumption that bus travel is a 'passive' mode. 


\section{$\underline{\text { Introduction }}$}

A growing body of literature addresses the relationship between travel modes, health and wellbeing more generally. First, in the context of increasingly sedentary lifestyles in high income cities, research has focused on the environmental and social conditions which hinder or encourage 'active' modes of travel, particularly for young people (de Vries et al., 2010; Frank et al., 2005; Kerr et al., 2007; Panter et al., 2008; Timperio et al., 2004). 'Active' travel is typically treated as shorthand for modes such as walking and cycling, which are assumed to be highly physically active, and contrasted with 'passive' modes such as car use, which are assumed to be fairly sedentary. Second, there has been interest in the ways in which such 'active' modes may be more likely to encourage the independent mobility of young people, enabling them to develop autonomy, confidence and social skills (Hillman et al., 1990; Mikkelsen and Christensen, 2009; O'Brien et al., 2000) The role of place has become prominent in this body of work, as greater consideration is given to the ways in which the interactions of local built environments, social environments and transport infrastructures might characterise the neighbourhoods in which young people live as either 'obesogenic' (e.g. Townshend and Lake, 2009) or 'salutogenic' (health promoting) (e.g. Frohlich and Potvin, 1999) environments. Thus, the ways in which aspects of the built environment such as street connectivity, housing density, distance to schools or other destinations interact with transport infrastructure (e.g. availability of public transport) and social factors are key to understanding one important element of how 'place' (broadly conceived) affects wellbeing: that of how far it shapes young people's propensity to be 'active' and independent in their travel behaviour (Carver et al., 2010; Giles-Corti et al., 2009).

In contrasting physically 'active' modes of transport with passive ones such as car travel, the role of public transport has been relatively neglected. Further, in focusing on transport modes as more or less healthy ways of moving through place, the role of transport itself as a place, and a place which may have intrinsic health benefits or costs, has also received rather less attention. In this paper, we focus on bus use in the context of a local policy which removes financial disincentives to travel by bus. We address the relationships between transport mode and wellbeing in terms of both the potential ways in which transport accessibility might affect the determinants of health and the broader role of the transport mode itself on wellbeing.

Our case study is London, where young people have been able to travel on the buses with no charge since 2005/6. In September 2005, the Greater London Authority (GLA) introduced free bus travel for 12-16 year olds (TfL, 2007). This fare exemption was extended a year later to include 17 year-olds in full-time education (TfL, 2006) and now also includes all 18 (and some 19) year-olds in full-time education or on a work-based learning scheme (TfL, 2010a). The stated aims of the scheme were "to help young people to continue studying, improve employment prospects and promote the use of public transport" (TfL, 2006, p7) and to "embed more environmentally sound travel habits from an early age" (TfL, 2007). Any social policy has direct and indirect consequences and sometimes unforeseen benefits and harms that go beyond those envisioned by policy-makers. Although the scheme was not introduced explicitly to 
address young people's health, the aims above clearly have some beneficial implications for determinants of health at both the individual level (through improving social inclusion and access to, for instance, education) and the population level (if they do succeed in decreasing future dependence on car travel). However, as politicians and policy-makers look to rein-in public spending, other postulated health consequences of free public transport become legitimate grounds for challenging such policies. For example, a Transport for London [TfL] Board member and former Minister for Transport in London has explicitly queried "the value of providing free bus travel for children when there was a nationwide push to combat childhood obesity" (GLA, 2010, p12), a view echoed by this local practitioner (a School Travel Adviser):

I would urge TfL to scrap concessionary bus fares for children in London.... They should be walking or cycling these trips for the sake of their own health and fitness. Yet many of them are taking the bus for just a stop or two - and getting fatter and fatter ... It is almost impossible to get secondary school kids on their feet or on their bikes in the face of the free [bus travel]. It's high time it was abolished. (Evans, 2011).

Such views reflect wider 'alarm about the threat of an 'obesity epidemic,' resulting in part from increasingly sedentary lifestyles in urban settings in high-income countries, [that] has focused attention on the potential of 'active transport' as one method for improving the physical and mental health of the population" (Steinbach et al., 2011, p1123). Although these impacts of fare concessions on physical activity have been the focus of recent concern, a range of hypothetical positive and negative effects on health and the determinants of health potentially accrue from providing free bus use for young people. Plausible impacts include: changes in levels of active transport, depending on whether bus trips replaced walking or car use; changes in road injury, as young people are more or less exposed to road danger as pedestrians; changes in assaults, as young people's exposure to risk changes; increases in access to education, training or work; decreases in social exclusion; decreasing dependence on future car travel; changes in access to bus travel for other users displaced by increased numbers of young people (Wilkinson et al., 2011). Measuring the impact of free bus travel on these outcomes requires quantitative assessment. However, we argue here that it is also necessary to explore, from the perspective of young people themselves, a broader view of how travel practices might relate to wellbeing, and to ensure that the pathways identified do not marginalise the less visible determinants of health, or the broader areas of wellbeing that might be important to young people. Drawing on qualitative data, this paper therefore aims to elucidate the various pathways that link travel behaviour (as mediated by free bus travel eligibility), the determinants of physical and mental health for young people, and the possible mechanisms by which travel mode choice affects wellbeing.

\section{$\underline{\text { Methods }}$}

We analysed young people's accounts of bus travel generated in interviews and focus groups, and notes of observations on London's buses. We included $11812-18$ year olds living in London in either interviews $(\mathrm{N}=25)$ with one, two, or three young people or larger focus groups $(\mathrm{N}=10)$. Our aim was to elucidate tacit, or everyday, influences on 
and effects of young people's transport mode choices, and to link these both to the direct health consequences of travel practices articulated by the research participants themselves and to the potential health effects that can be deduced from the behaviours they describe. The topic guides therefore focussed on generating stories by asking about: modes of travel to and from main daytime destination, and in the evenings and at weekends; experiences, benefits and disadvantages of different transport modes; experiences of interactions with others when travelling. Towards the end of the interviews we directly asked participants about the perceived health impacts of bus travel and their ideas about free bus travel. Participants were recruited from four London boroughs and from young people engaged in the 'Young Scientists' programme at LSHTM. ${ }^{1}$ The four boroughs were chosen to represent two outer London boroughs: Havering [Hav] and Sutton [Sut], and two inner London, Islington [Isl] and Hammersmith and Fulham [H\&F] across Greater London which had a range of transport availability (see Figure 1).

\section{Figure 1: Location and bus density of four London boroughs}

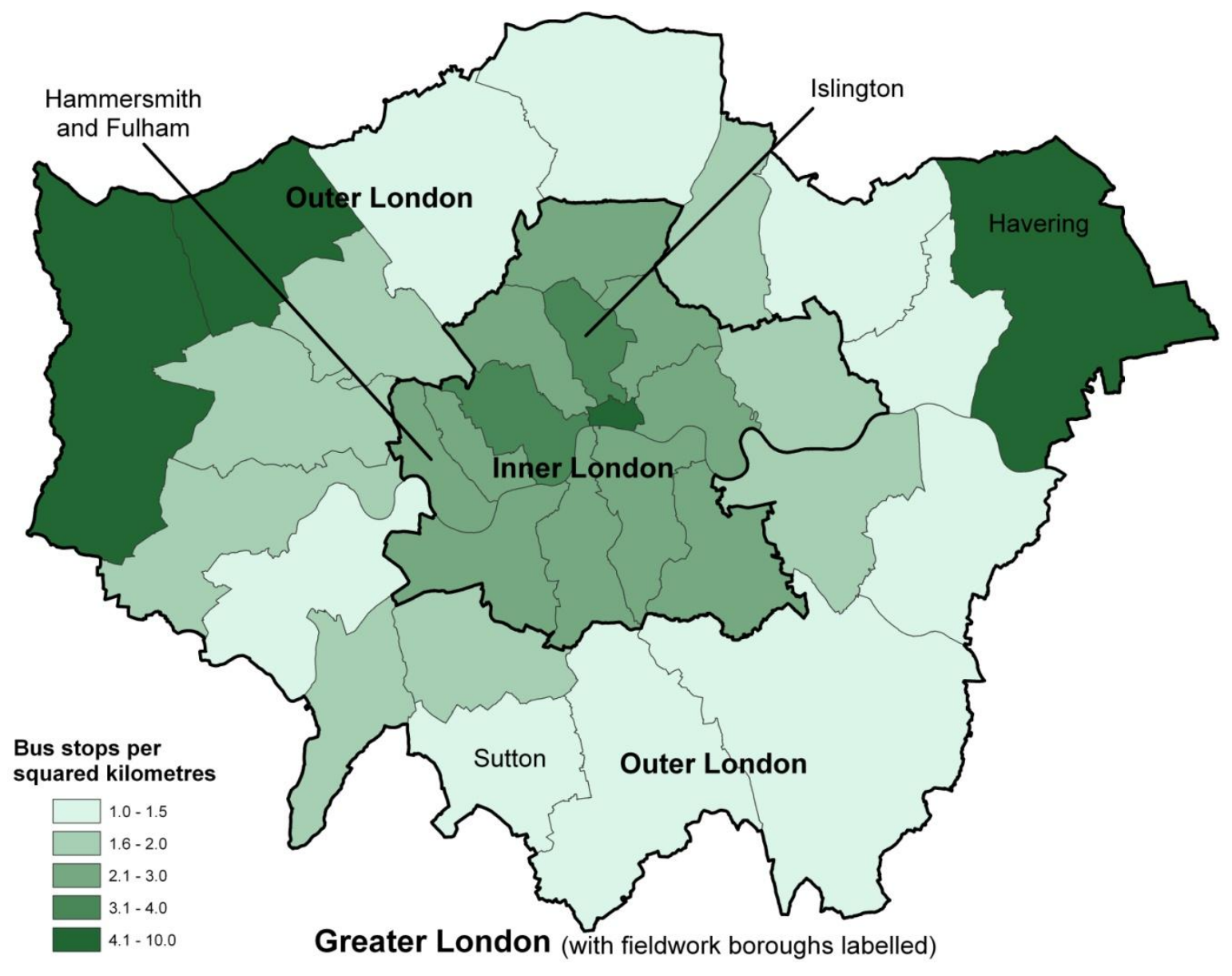


Within each borough participants were recruited purposively to include a range of participants (by age, gender, ethnicity, socio-economic status and typical mode of transport) (see Table 1) from institutions including schools, academies, youth clubs and a pupil referral unit. In addition, we drew on observational data compiled by the research team over the course of the fieldwork. Given the different patterns of travel across the year (both by season and in school/term time), fieldwork took place in several batches between February 2010 and August 2011, some five or six years after free bus travel had been introduced. Transcripts and notes were analysed qualitatively, drawing on techniques from the constant comparative method (Strauss, 1987), including detailed open coding of early segments of data, close attention to comparisons within the data (for instance in comparing young people's accounts in stories and in addressing direct questions) and context (e.g. in comparing accounts in focus groups and interviews). All authors were involved in analysis: identifying key themes from early transcripts, discussing coding frameworks and coding data for analysis. In direct quotes from the data, all names and other potential identifiers have been anonymised. Extracts are tagged with an identifier for borough or 'Young Scientists' [YS] programme, gender and age or age range (for focus groups).

Table 1: Characteristics of study participants $(\mathrm{N}=118)$

\begin{tabular}{|l|l|l|}
\hline & & $\mathrm{N}(\%)$ \\
\hline London & Hammersmith \& Fulham & $23(19 \%)$ \\
& Havering & $28(24 \%)$ \\
& Islington & $20(17 \%)$ \\
& Sutton & $22(19 \%)$ \\
& Other & $25(21 \%)$ \\
\hline Gender & Female & $65(55 \%)$ \\
& Male & $53(45 \%)$ \\
\hline Age & $12-13$ years & $26(22 \%)$ \\
& $14-15$ years & $70(59 \%)$ \\
& $16-18$ years & $22(19 \%)$ \\
\hline Ethnicity & White British & $52(44 \%)$ \\
& White other & $8(7 \%)$ \\
& Black & $26(22 \%)$ \\
& Asian & $8(7 \%)$ \\
& Mixed & $18(15 \%)$ \\
& Other & $6(5 \%)$ \\
\hline Area & Fifth 1 (most deprived) & $34(31 \%)$ \\
deprivation of home & Fifth 2 & $24(22 \%)$ \\
& Fifth 3 & $13(12 \%)$ \\
& Fifth 4 & $20(18 \%)$ \\
& Fifth 5 (least deprived) & $18(17 \%)$ \\
\hline
\end{tabular}

$\dagger$ Fifths defined with reference to Greater London as a whole. Numbers do not add up to 118 for area deprivation because of missing postcode data on 9 participants. 


\section{Findings}

\section{Bus use replaces walking for short trips:'because it's there, and it's free'}

For short journeys, when there is no cost to the user, and buses are available and accessible, many young people talked about using the bus to go "short distances, literally three stops" (Sut 14-18, M). Indeed, distances travelled by bus could be extremely short:

[M]y dad takes me a couple of metres down the road, it's only about 200 metres down the road. And then from then I go and get the bus to school. And then there's only a few metres from where I get off the bus to go to school. [...] I'm on the bus for roughly about less than a minute. (Hav, M, 14)

Bus travel was widely described as the default option for short trips, for which the only major constraint on bus use was lack of immediate accessibility:

If I'm walking...past a...bus stop and the bus is making its way up I just jump on.

But if not, I just keep walking, I can't be bothered to wait. (Isl, F, 16)

That bus travel was the automatic choice, despite potential disadvantages, was suggested by reflections that on occasion by the time they got to their destination "it would have been much quicker if we just walked there" (Sut, M, 14-18). The removal of any economic disincentive was acknowledged as the reason for 'jumping on' for a couple of stops now being the normal choice for what would otherwise largely be walking trips:

I think that the fact that knowing the bus is free helps me want to get on the bus... if I had to pay I would not get on the bus. (Isl, F, 16)

[I] you didn't have the free bus travel, how would you get to school do you think? I'd have to walk, I'd probably walk. ...[B]ut I'd have to leave much earlier because it's about a half an hour walk, five minute bus journey. I'll take the bus any day. (Hav, M, 16)

Walking was, however, generally only considered to be a candidate mode for short journeys. For longer trips, walking was rarely considered a viable option even if there were costs or other disincentives to alternatives and, in the absence of free bus travel, hypothetically, young people thought they would typically either forgo the journey, pay, or persuade parents to provide lifts, depending on the need. As one respondent noted in relation to asking for lifts, "parents always seem to be conveniently free" (Sut, M, 14-18). This is not to say that the fare exemption has universally eliminated all walking trips: in some instances, despite bus travel being free, young people would opt to walk rather than take the bus:

[Q]uite often, during the summer I'd walk home from school. Even though it is a good 50 minute, hour long walk, but sometimes it's just easier than waiting for the bus and then getting all crammed on it. (Sut, F, 15-16).

[I] walk [to school], because I live nearby so...I'd feel a bit stupid getting the bus. (Sut, M, 14-18). 
Nevertheless, as these instances demonstrate, opting to walk would usually be in response to perceived conditions (having to wait for a bus, the crowdedness of the bus or the 'stupidity' of getting a bus short distance) rather than a proactive decision in light of the health (or other) benefits of travelling by foot. In this respect, it would appear that for the most part secondary school children are inclined to persevere with trying conditions before opting to walk:

$[\mathrm{M}] \mathrm{y}$ friend who lives in between [Springfield] and [Newville] said it got to a point where for two weeks, every day, the bus...was too full to just stop for her. So in the end she just had to leave her house half an hour earlier and walk. (Sut, F, 14-18).

When specifically asked, many young people enjoyed cycling, and would even like (in theory) to cycle to school. However, cycling was rarely mentioned as a candidate mode of routine transport for getting to school or other locations, and rarely mentioned spontaneously as a possible alternative to a walking or bus journey. Rather, cycling was largely discussed as a leisure activity, particularly for boys who reported, for instance, that sometimes: "we just ride our bikes and cruise" (H\&F, M, 15).

\section{Physical activity in the transport system}

The widespread use of buses to travel short distances would appear to suggest that removing any economic disincentive to walk has indeed reduced levels of walking, and thus physical exercise, among this section of the population. However, our data suggest that such a conclusion may be premature for two reasons. First, for some, having free bus travel generated additional walking journeys that would either have not been undertaken without the fare exemption or would have been carried out as a car passenger.

If I didn't have free travel...I wouldn't be going places I would be probably staying quite local and through using free travel it means I can go places that I've always wanted to go (Sut, M, 15).

By the same token, other journeys might be undertaken less often if free bus travel was not available. As one focus group participant put it when asked how journeys would change without free bus travel, "I don't think anyone would really go out as much to be sociable" (Sut, F, 15-16). She goes on:

[S]ometimes when I go out with my friends I get three buses there and three buses back, depending on where I'm going, and I wouldn't pay that much to spend three hours out, because you think about it..., you're going to end up paying a lot of money for just going out with your mates for three hours. You're already trying to save money doing stuff that doesn't cost us. [You don't want to be paying for] getting there as well. (Sut, F, 15-16).

Elsewhere, another focus group participant put this more succinctly, stating that by having the free bus pass:

I go places more...than I would normally [without the free pass] .... Like football, just places to out with my friends [I go to] more... if I had to pay for the bus then it would cost more to go out...than I've got (Sut, M, 14-18). 
A marked geographical distinction was apparent in the data. In inner city areas, with a higher density of bus stops and routes, young people would report that bus trips tended to displace walking trips, whereas in more suburban areas, with further to walk to their nearest bus stop, bus trips were more frequently reported to have displaced car trips. As one young suburban participant put it when asked how they would get to school if they did not have free bus travel: "[m]y mum and dad would drive me" (Sut, M, 13-16). Similarly another focus group participant from the same borough told us how they "hardly ever go in the car anymore" (Sut, F, 14-18). In suburban areas in particular, then, the free bus pass generated instances of physical activity by encouraging hybrid walking and bus journeys instead of door-to-door lifts by parents or guardians.

Across both inner London and the suburban boroughs, a significant proportion of walking is done within the transport system, with accounts suggesting exercise within the course of a 'bus journey' itself. Being able to travel without charge on buses meant that young people felt less limited in terms of their transport choices, and would often take journeys involving multiple buses (and inter-changes) if the most direct bus did not arrive:

[B] ecause I have the free [bus travel] I'm not restricted to get a certain bus, so I can get any bus, get off and...change, so that saves me time (H\&F, M, 12-17).

Such bus-changing strategies could also be adopted in order to ensure a more comfortable, less crowded journey, or were even undertaken simply for fun. Regardless of motive they would involve walking, or even running, between buses and bus stops. While strategies to avoid unnecessary walking as the main mode to a destination pervaded the accounts, this preference for less active ways of travelling did not necessarily extend to within the transport system itself. For example, respondents would report choosing to stand on the bus (for very short journeys) rather than sit, and on occasion turning a public transport journey into a physical challenge:

I don't really sit on the bus, I, you know by the doors, I just stand there. ...I think there's no point sitting because it's only going to be a minute journey, so I just stand up for that. [...] (Hav, M, 14).

Me and Costos race [up train station steps] to see who gets up there first every morning ... I usually win ... and from there we walk (YS, M, 14-15)

Crucially, riding the bus did not necessarily connote sedentary behaviour (cf. Hardy et al., 2007; Santos et al., 2005), in particular where no seat was available on the bus or where adjacent seats for groups of young people were not available. This finding was reiterated during observations made during fieldwork. These showed that young people using public transport, in particular on their way home from school, would often be active during their journeys - moving between friends sitting on different parts of the bus, running to or between buses, running off the bus after nearly missing their stop and even using metal bars intended to help passengers support themselves as ad hoc exercise frames. Thus for a secondary school child in London, public transport journeys can be highly active events. 


\section{Fare exemptions and the reduction of transport poverty}

Universal free bus travel for young people removes a key potential financial barrier to social inclusion: that of transport costs. Although few young people in our interviews were explicit about the impact of free bus travel on their own ability to take part in, for instance, education or social activities, there were occasional accounts of increased opportunities for access to sport and leisure:

[For t] he local sports centre near me...we've got to get a bus to get to it. So my brothers do that, and my mum takes my sister because they have like that little baby club thing there. So if a bus, the price went up, my mum wouldn't take my sister to the little clubs where she can meet other little kids. And my brothers probably wouldn't go to the gym at all. (Sut, F, 15-16).

Notably, the instances of increased opportunity of access recounted were often groupbased activities, with the intervention enabling families to more easily afford to go on outings:

When I was younger because my mum was pregnant at the time... me and my dad used to go up London because it was free for me... We used to go the Science Museum and things like that... so it was quite fun. (Sut, M, 13-16).

To some extent our data generation method (with most young people interviewed in small groups) perhaps discouraged disclosures of financial barriers for less well off young people. One young man, for instance, prefaced his account of the difficulties his family would have without the fare concession with a plea to other interview participants not to repeat his circumstances outside the group (Isl, M, 15). However, the potentially dramatic impact of free bus travel on social inclusion was evident in the taken-forgranted nature of inclusion implicit in young people's responses. First, across the data set, at every age, in outer and inner London, young people's accounts suggested their independent access to both local and more distant destinations by bus was a routine expectation, a normal and unquestioned part of everyday life:

I just get two buses to school, and on the weekends same, I just get the bus anywhere. Like sometimes it can be far like the West End, or not, it could just be like [local high street] or something. (Sut, F, 15-16 [emphasis added]).

In this respect, transport poverty was notably absent as a salient concept for the participants in this research. Indeed the taken-for-granted nature of being able to afford to get anywhere is perhaps indicated by the rather extreme response of one participant (echoed less succinctly by others), who told us that if she could not use the buses for free she "wouldn't come to school" (H\&F, F, 15). Across the boroughs, young people emphasised the ease of getting around, and indeed the range of sites that might be visited by bus:

I take the bus every day... [for] going to school, going to dancing, going to see my friends, maybe going to church... because it's free ... I can go to different places, so anywhere I want to go (Hav, M, 15)

[T] hat's [fare exemption] really helpful, whenever I really need to go anywhere it's just, it's no hassle (Sut, M, 14-18). 
The 'hassle' of having to pay, and the fragility of young people's entitlement to exempted bus fares, was made most clear during a focus group with young people in Hammersmith and Fulham. One participant had had his right to free travel rescinded by Transport for London (as part of the 'Behaviour Code' penalties introduced in relation to some travel concessions for young people (TfL, 2010b)):

[W]hen I didn't have [free bus travel] I did struggle in terms of not getting everything done because I didn't have that freedom to get on a bus (H\&F, M, 1217).

Similarly, one young man noted of four friends who had their passes taken away: "It puts a strain on their social activities because they can't go out as much" (Hav, M, 15). This suggests a key element of the social inclusion facilitated by free bus travel: as well as achieving some success in "helping young people to unlock education, sport, leisure and employment opportunities" (TfL, 2007), as the sport centre and football trips described above attest, the scheme has also furthered the sociability of young people.

\section{Fare exemptions and sociability}

Free travel not only opened up the range of places that young people could go in London, but it also enabled young people to maintain friendship groups. As well as enabling young people to travel in order to maintain social relationships with a broad network of friends, our observational and interview data also show that the fare-free nature of bus travel for young Londoners facilitated the treatment of London buses as a site for valued socialisation. As one focus group participant summarised:

It's one of the main things you do on the bus, if you go out with someone you sit down and you talk about things. (Sut, M, 14-18)

Eliminating the financial barrier to bus travel enables buses to become key public spaces in the city for young people to convene and socialise both as part of their school journeys but also in the evenings, during school holidays and at weekends: One participant explained why they sometimes spontaneously catch a bus:

[L]ike we'll just be bored and we don't want to go home, so we'll just hop on a bus and we'll go anywhere. (H\&F, F, 12-17).

Picking up on this point, a male participant in the same focus group added:

I find it's more girls that do that because my sister does that as well. She goes around with her friends all the time on buses everywhere. (H\&F, M, 12-17).

This is not to say that prior to the intervention buses had not been treated by young Londoners as a space in which to socialise with their peers. Rather, by rendering bus use free for young people on an unlimited basis, the intervention dramatically shifted the degree to which buses could be used in this way. The bus network became a part of the freely accessible geography of London for all young people, not only as a way of getting to and from destinations but also a destination in itself: 
Me and my mates got a bus because...it [the bus journey] was really long... [W]e had a good sort of chat and stuff, it was really good. (Isl, M, 12-13 [emphasis added])

Notably, this use of the bus network as a setting in which to socialise appeared to be particularly prevalent among groups of school girls. As one group at an all girls school described it, there operates a "kind of loyalty to get on the bus with your friends" (Sut 1516), and the fact that the buses are free to use provides a context in which this loyalty can be demonstrated without any (direct) financial cost.

Far from reporting it as a passive way of travelling between two points, then, a tendency emerged in our interviews and focus groups for the young people to frame bus travel in terms of sociability. This contributed to the attractions of bus travel compared with other modes. As one focus group participant put it, their walk to school is pretty straightforward, but "most of my mates get the bus anyway, so, like, I go with my mates" (Isl, M, 12-13). Another noted the greater sociability of buses compared with car travel: My mum or dad would drive me if I want them to but it's like I said you meet friends on the bus and things like that. (Sut, M, 13-16).

This is important on two counts when it comes to considering implications for wellbeing. First, by providing a means (as well as a setting) for young people to convene, the intervention arguably enables them to improve their health outcomes through the very act of socialising (Holt-Lunstad et al., 2010). Second, in terms of inequalities in health, the scheme enables all members of a given peer group to travel together, thus arguably playing a key role in reducing transport exclusion (esp. Social Exclusion Unit, 2003) and its harmful health consequences (Cattell, 2001). Travelling 'together' was widely reported as important, with many accounts of groups of young people choosing to travel by bus because this meant the whole group could travel together. The taken-for-granted accounts, above, of unfettered access to getting around London by bus were shared by young people from different socio-economic backgrounds in the study, and use of buses for some journeys was near universal among the research participants. Across the large data set we generated, the only statements relating to financial problems in getting around London related to losses or confiscation of the pass card used to show their entitlement. For almost all young Londoners, 'transport poverty' was, therefore, insignificant in terms of its reported impact on everyday lives.

\section{Learning independent mobility: navigating place and social interaction}

Linked to these points about sociability and inclusion is the equality of opportunity that the fare exemption provides all young people in London when it comes to experiencing the city and gaining independence. The 'experience of the city' that the policy afforded is two-fold, comprising both opportunities to experience otherwise less accessible geographical parts of the city and opportunities to develop skills in socially navigating the city. Access to free travel meant young people, from early ages, were better able to explore London, and to develop an understanding of the city's geography: 
When we [my friends and I] was in London we just saw a bus that was going...towards Oxford Street, didn't know exactly where it was going ....and we get on it, we're lost, see, see where we end up... (Hav, M, 16).

I think if you get the bus a lot you can try and, like, vary it [the routes you take] up so you get to know London (Isl, M, 12-13)

In instances where young people almost purposefully 'got lost' on the bus network the free bus provided not only a means to get lost, but also a means to return to more familiar surroundings. Thus, when our respondents found themselves in unknown parts of the city they would typically "take the same bus in the opposite direction" (H\&F, F, 12-17) as a means to re-orient themselves. By holding a free bus pass, young people are able to mitigate fears and anxieties they might have about becoming stranded in a foreign quarter of the city with limited means to extract themselves from it.

Having access to free travel increased the degree to which young people were able to develop skills in social settings and interactions. At one extreme, stories and experiences of 'odd people' (Whyte, 1988, p25) on buses were dotted through the young people's accounts - for example "the old guy with the headphones that dances on the bus" and "the wizard man" who were described during one focus group (Sut, M \& F, 14-18). In contrast to these stories, which were often clearly part of the common stock of narratives shared by friendship groups, were the more mundane experiences of everyday encounters with a range of other bus users. Interactions with others passengers routinely included young people of different ages or communities, commuters, tourists, older citizens, and mothers with buggies. Dealing with mundane interactions and, on occasion, more detailed conversations provided opportunities for developing the necessary skills to navigate the crowded transport spaces of the city, in a social context in which young people may have limited other opportunities to interact with a range of adults. Older citizens were reported as being particularly likely to engage young people:

F1: I don't think there's been a time that I've got on a bus and there hasn't been an old dear that's got on and...[s]he's sat in the front seat and just starts talking to the other people her age

F2: Or even just to us[.... I've had many a conversation with older people, not so much like 30 to 50 year olds they...keep to themselves (Sut, F, 18)

The most common type of interaction reported was in relation to giving up a seat to a more deserving passenger, with participants often listing the categories of 'more deserving' passengers: the elderly, pregnant woman and those with disabilities were usually cited. This perceived responsibility to give a seat up would often prompt reflection among respondents, suggesting that through bus travel, civic ways of interacting in public were being learned:

Sometimes it [offering your seat]...bypasses your mind, though, because sometimes, I realise...when I've got off the bus, and I think to myself, maybe I should have let that person take my seat. I just didn't think of it at the time, so. (Isl, M, 12-13) 
On occasion, such learning was reportedly rather more didactic:

Every now and again [you interact with adults]..., like if you are sitting down [on the bus] and... just leave your rubbish there, they are like "have you forgot something?" (Isl, M, 12-13)

In terms of future attitudes to public transport, such experiences also, of course, mean that young people are exposed to the 'normal' use of public transport by a wide section of the population, and this may help to combat perceptions of buses as a stigmatised transport mode compared with car use. This is not to say that free bus travel enabled these experiences of social interaction and growing independence, but rather that it levelled-off young Londoners' opportunities to travel on the bus network. The policy has heightened young people's capacity to broaden their horizons and experience unfamiliar places and social interactions and to develop the necessary routine interactional skills needed to travel a busy city. Critically, in terms of wellbeing, while these places and interactions were often of a type which might be viewed as risky, having a free bus pass out of a given situation apparently reduced the significance attributed to those risks by young people.

\section{$\underline{\text { Discussion }}$}

We have drawn on young people's accounts of travelling in London, where they have (for the last five or six years) been able to use buses with no charge, to explore the ways in which transport mode choice might impact on wellbeing. Policy debate has focused on one particular potential outcome of accessible bus travel: that of potentially reducing the amount of 'active' travel young people do. Our data initially suggest that fare exemptions for young people appear to result in the displacement of some walking journeys, and indeed even short (a few hundred metre-long) journeys. However, we have also shown that this policy intervention does not, straightforwardly or exclusively, encourage travel 'passivity' among those subject to it. Indeed, in several respects the policy facilitates 'active,' health-promoting experiences. These range from instances of active travel as they have been conventionally understood in the literature: walking to/from/between bus stops instead of being driven in a private vehicle (especially in more suburban areas); increased numbers of walking trips as part of the additional journeys undertaken as a result of having a free bus pass; and more walking, and even running, within the 'bus journey' itself as young people are more inclined to interchange buses given there is no longer a financial cost in doing so. Any analysis of a free public bus transport intervention needs to acknowledge that buses largely take fixed routes and stop at designated points along these routes. They do not provide a door-to-door service, and so 'bus journeys' almost always comprise trips made on foot too: as research in other settings has noted, a considerable amount of walking happens within a transport system (Besser and Dannenberg, 2005; Julien and Carré, 2002). Thus exemption from bus fares at one and the same time creates the conditions for the displacement and the generation of walking trips. Whether generation outweighs displacement (and indeed whether the small changes involved in total 'active' travel time have any health outcome implications) requires empirical quantitative assessment. One study of older citizens in England suggested that free bus travel has had a protective effect on obesity (Webb et al., 
2011): whether this is also true for young people is a question that we are exploring elsewhere (Wilkinson et al., 2011).

However, in a general sense, our data suggest that an oppositional or explicit (e.g. Mota et al., 2007; Van Dyck et al., 2009) positioning of urban bus travel as 'passive transport' in contrast to the 'active' modes of walking and cycling may be inappropriate. Rather than assume time spent travelling by bus necessarily represents inactive or sedentary time, and by implication 'unhealthy' time, we need to look more closely at how young people actually conduct themselves on public transport. In analysing young people's accounts of travel in London, we suggest that bus travel, and in particular bus travel in groups that is facilitated by universal fare-exemptions for schoolchildren, can be 'active' in two senses. First, as above, bus journeys can be active rather than passive: simply congregating and socialising over the course of the bus journey (and in particular over the course of bus journeys home from school) entails considerable movement, engagement and social interaction. Second, the 'active' experiences encouraged by having access to free bus travel certainly extend beyond the generation of some walking trips. Pervasive through the accounts we collected was the sense that this fares policy opened up the bus network as a set of public spaces for young people; public spaces that are 'unexceptional' but nonetheless valuable to users' wellbeing (esp. Cattell et al., 2008). Of importance here are both the socio-spatial conditions of the bus journey (that it takes place in an enclosed space that is co-occupied by adults but in which certain areas, typically the rear of the top deck, can be appropriated by groups of children) and the universal nature of the fare exemption. This policy intervention rendered buses freely accessible mobile public spaces for all young people in London. These particular public spaces are sites in which this group could get somewhere else, but also in which they could simply be - to gather, socialise, engage with one another, talk, share experiences and even be physically active. Precisely at a time when social scientists and commentators have argued that the inbetween public spaces of cities are becoming increasingly subject to 'revanchist' urban politics (Mitchell, 2003; Ruppert, 2006; Smith, 1996), and in turn less hospitable to vulnerable sections of the population such as young people (esp. Valentine, 1996), the application of this fares policy inadvertently produced a readily accessible network of spaces understood by our participants to be "[p]ublic, definitely, very public" (Sut, M, 14-18). At the intersection of environmental conditions and policy, therefore, these spaces that have been opened-up for young people are used in sociable, engaged and exploratory ways which we argue represent important types of 'activity.'

We argue that a more nuanced approach to the term 'active travel' may be useful, which factors in the "balance of inactivity and activity in different domains (transport, occupation, domestic and leisure) of everyday life" (Brown et al., 2009). Such an approach would recognise, as some researchers (e.g. (Wen et al., 2010, p2)) already have, the overlaps, rather than imply a distinction, between public transport and active travel. Beyond this, though, the approach we propose would recognise that for studies of transport-related behaviour 'activity' includes more than narrowly-defined practices such as walking and cycling. 
We have also illustrated how free bus travel potentially mitigates transport poverty, allowing all young Londoners access to the city. Notably, it has been shown that this capacity to participate "in social, cultural and leisure activities is very important to people's quality of life and can play a major part in meeting policy goals like improving health" (Social Exclusion Unit, 2003, p16). Crucially, this ability was taken for granted for these young people, given that most had never experienced financial barriers to travel. Not surprisingly, perhaps, transport poverty was most striking in its absence in our data, with no reported financial barriers to getting around.

Other potential pathways by which bus accessibility affects wellbeing are suggested in accounts relevant to the more tangential determinants of health. By encouraging travel that is independent of parents or guardians, free bus use militates against increasingly overprotected and 'bubble-wrapped' experiences of childhood in built-up areas (Carver et al., 2010; Hillman et al., 1990; O'Brien et al., 2000), and opens-up a network of places for young people to develop their skills in navigating both the physical space of their city and routine interactions with a cross section of the public. At the same time, our data suggest that free bus travel enhances young people's ability to forge and maintain links with friends and family from across the city, potentially helping to develop stocks of 'bridging social capital,' suggested as protective for health (De Silva et al., 2005; Kim et al., 2006) and essential for wellbeing.

This paper has drawn on accounts from a range of young people in London from different localities. However, it was not a random sample, and we drew on accounts of transport behaviour, rather than directly measuring use of transport modes. Our design did not therefore aim to measure use of buses or other transport modes, or to evaluate the impact of free bus use on young people's health (or indeed the consequent possible effects on other bus users), but rather to outline some of the key pathways linking travel mode and health for young people. A policy such as a public transport fare exemption is likely to have a range of effects, some health promoting, others less positive. Some of these effects can, in theory, be assessed quantitatively, such as the distances young people walk. Others, we suggest, may be important to young people's wellbeing, but be rather difficult to measure, such as the implications of providing a means for all young people to participate in a public arena. A limitation of the analysis presented here is that we have focused largely on the data set as a whole, and the findings that were common across ages, localities and genders. However, the relationships between travel use and health are of course also likely to be mediated by young people's particular circumstances (O'Brien et al., 2000), and to change with age. Although we argue that the universal provision of free bus travel has implications for all young people in terms of removing an important barrier to participation, this may well have larger impacts on those in more deprived circumstances, for instance. Similarly, the findings on independence might need to be balanced with data on the risks of independent travel differently at different ages. More work is needed on unpacking the variations among young people in the relationships between travel mode and wellbeing. 


\section{$\underline{\text { Conclusions }}$}

Our data suggest that the pathways linking free bus travel and wellbeing for young people are likely to have contradictory effects on health. In terms of impacts on physical activity, eliminating the cost of getting on a bus both disincentivises and generates travel by foot. Research is now needed on how far changes in transport mode are likely to affect such direct determinants of health. However, we have also identified a number of pathways by which universal access to bus travel might positively affect wellbeing more generally. It broadens the capacity for all young people to travel independently of adult supervision. It opens up a network of public, mobile places in which young people can actively maintain their often dispersed "virtual" community of friends" (Morrow, 2000, p150) in a relatively accessible setting. These effects may be more difficult to measure in quantitative studies, but are crucial to the ability of young people to have healthy, independent lives. Finally, we suggest that the opposition of walking and cycling as 'active' modes of travel with motorised forms of transport as 'passive' is problematic. Rather, for young people in London bus travel can be both a physically and socially active experience. The intervention (and the data we have collected) problematises accounts that have presented 'non-motorised travel' and 'independent mobility' among children as coterminous (cf. Hillman et al., 1990; Whitzman et al., 2010). It is not so much the mode of travel per se that shapes independence, as the degree to which the mode is unrestrictedly accessible. As we pay more attention to the interface between how we travel in cities and our health, and at a time when social context has been recognised for its importance to health research, this paper demonstrates that urban public transport networks can be important 'places' for the study of health-related behaviours.

\section{$\underline{\text { Notes }}$}

${ }^{1}$ The LSHTM 'Young Scientists' programme offers work experience in an academic setting to young people aged 14-18 from schools in London. For further information see: http://www.lshtm.ac.uk/aboutus/introducing/volunteering/ysp/index.html

\section{Conflict of interest}

None

\section{Acknowledgements}

The 'On the buses' project is funded by the National Institute for Health Research Public Health Research programme (project number 09/3001/13). AG contributed to this project during a Post Doctoral Research Fellowship supported by the National Institute for Health Research. The views and opinions expressed in this paper are those of the authors and do not necessarily reflect those of the NIHR PHR programme or the Department of Health. We would like to thank: Phil Edwards, Paul Wilkinson and Mark Petticrew from the 'On the buses' team for input into this paper; Chris Lines, Suzanne Lutchmun, Alex Philips, Richard Jeremy and Steven Salmon from our Steering Committee for their support; two anonymous referees for helpful comments on an earlier draft; and most 
importantly, the young people who participated in our research and everyone who generously helped us with participant recruitment.

\section{$\underline{\text { References }}$}

Besser, L.M., Dannenberg, A.L., 2005. Walking to public transit: steps to help meet physical activity recommendations. American Journal of Preventive Medicine 29, 273280 .

Brown, W.J., Bauman, A.E., Owen, N., 2009. Stand up, sit down, keep moving: turning circles in physical activity research? British Journal of Sports Medicine 43, 86-88.

Carver, A., Timperio, A., Hesketh, K., Crawford, D., 2010. Are children and adolescents less active if parents restrict their physical activity and active transport due to perceived risk? Social Science \& Medicine 70, 1799-1805.

Cattell, V., 2001. Poor people, poor places, and poor health: the mediating role of social networks and social capital. Social Science \& Medicine 52, 1501-1516.

Cattell, V., Dines, N., Gesler, W., Curtis, S., 2008. Mingling, observing, and lingering: Everyday public spaces and their implications for well-being and social relations. Health \& Place 14, 544-561.

De Silva, M.J., McKenzie, K., Harpham, T., Huttly, S.R.A., 2005. Social capital and mental illness: a systematic review. Journal of Epidemiology and Community Health 59, 619-627.

de Vries, S.I., Hopman-Rock, M., Bakker, I., Hirasing, R.A., van Mechelen, W., 2010. Built environmental correlates of walking and cycling in Dutch urban children: results from the SPACE Study. International Journal of Environmental Research and Public Health 7, 2309-2324.

Evans, R., 2011. Scrap free bus travel for kids, Boris - it's fueling obesity. Local Transport Today 566.

Frank, L., Schmid, T., Sallis, J.F., Chapman, J., Saelens, B.E., 2005. Urban form relationships with walk trip frequency and distance among youth American Journal of Health Promotion 21, 305-311.

Frohlich, K.L., Potvin, L., 1999. Health promotion through the lens of population health: Toward a salutogenic setting. Critical Public Health 9, 211-222.

Giles-Corti, B., Kelty, S., Zubrick, S., Villanueva, K., 2009. Encouraging walking for transport and physical activity in children and adolescents: how important is the built environment? Sports Medicine 39, 995-1009.

GLA, 2010. The Future of London's Buses - Transport Committee Seminar, 8 December 2009 [Transcript]. Greater London Authority, London. 
Hardy, L.L., Bass, S.L., Booth, M.L., 2007. Changes in sedentary behavior among adolescent girls: A 2.5-year prospective cohort study. Journal of Adolescent Health 40, $158-165$.

Hillman, M., Adams, J., Whitelegg, J., 1990. ONE FALSE MOVE... A Study of Children's Independent Mobility. PSI Publishing, London.

Holt-Lunstad, J., Smith, T.B., Layton, J.B., 2010. Social relationships and mortality risk: a meta-analytic review. PLoS Med 7, e1000316.

Julien, A., Carré, J.-R., 2002. Cheminements piétonniers et exposition au risqueRisk exposure during pedestrian journeys. Recherche - Transports - Sécurité 76, 173-189.

Kerr, J., Frank, L., Sallis, J.F., Chapman, J., 2007. Urban form correlates of pedestrian travel in youth: Differences by gender, race-ethnicity and household attributes. Transportation Research Part D: Transport and Environment 12, 177-182.

Kim, D., Subramanian, S.V., Kawachi, I., 2006. Bonding versus bridging social capital and their associations with self rated health: a multilevel analysis of 40 US communities. Journal of Epidemiology and Community Health 60, 116-122.

Mikkelsen, M., Christensen, P., 2009. Is children's independent mobility really independent? A study of children's mobility combining ethnography and GPS/mobile phone technologies Mobilities 4, 37-58.

Mitchell, D., 2003. The Right to the City: Social Justice and the Fight for Public Space. The Guildford Press, New York.

Morrow, V.M., 2000. 'Dirty looks' and 'trampy places' in young people's accounts of community and neighbourhood: implications for health inequalities. Critical Public Health 10, 141-152.

Mota, J., Gomes, H., Almeida, M., Ribeiro, J.C., Carvalho, J., Santos, M.P., 2007. Active versus passive transportation to school - differences in screen time, socio-economic position and perceived environmental characteristics in adolescent girls. Annals of Human Biology 34, 273-282.

O'Brien, M., Jones, D., Sloan, D., Rustin, M., 2000. Children's independent spatial mobility in the urban public realm. Childhood 7, 257-277.

Panter, J.R., Jones, A.P., van Sluijs, E.M.F., 2008. Environmental determinants of active travel in youth: A review and framework for future research. International Journal of Behavioral Nutrition and Physical Activity 5.

Ruppert, E., 2006. Rights to public space: regulatory reconfigurations of liberty. Urban Geography 27, 271-292. 
Santos, M., Gomes, H., Mota, J., 2005. Physical activity and sedentary behaviors in adolescents. Annals of Behavioral Medicine 30, 21-24.

Smith, N., 1996. The New Urban Frontier: Gentification and the Revanchist City. Routledge, London.

Social Exclusion Unit, 2003. Making the Connections: Final Report on Transport and Social Exclusion. Office of the Deputy Prime Minister, London.

Steinbach, R., Green, J., Datta, J., Edwards, P., 2011. Cycling and the city: A case study of how gendered, ethnic and class identities can shape healthy transport choices. Social Science \& Medicine 72, 1123-1130.

Strauss, A., 1987. Qualitative analysis for social scientists. Cambridge University Press, Cambridge.

TfL, 2006. Transport for London News. Transport for London, London.

TfL, 2007. Pan-TfL developments: Fares and Ticketing, Free travel for children. Transport for London, London.

TfL, 2010a. Getting around with discounts. Transport for London, London.

TfL, 2010b. Young persons behaviour code, Penalty fares and prosecutions. Transport for London, London.

Timperio, A., Crawford, D., Telford, A., Salmon, J., 2004. Perceptions about the local neighborhood and walking and cycling among children. Preventive Medicine 38, 39-47.

Townshend, T., Lake, A.A., 2009. Obesogenic urban form: Theory, policy and practice. Health \& Place 15, 909-916.

Valentine, G., 1996. Children should be seen and not heard: the production and transgression of adults' public space. Urban Geography 17, 205-220.

Van Dyck, D., Deforche, B., Cardon, G., De Bourdeaudhuij, I., 2009. Neighbourhood walkability and its particular importance for adults with a preference for passive transport. Health \& Place 15, 496-504.

Webb, E., Netuveli, G., Millett, C., 2011. Free bus passes, use of public transport and obesity among older people in England. Journal of Epidemiology and Community Health.

Wen, L.M., Kite, J., Rissel, C., 2010. Is there a role for workplaces in reducing employees' driving to work? Findings from a cross-sectional survey from inner-west Sydney, Australia. BMC Public Health 10. 
Whitzman, C., Romero, V., Duncan, M., Curtis, C., Tranter, P., Burke, M., 2010. Links between children's independent mobility, active transport, physical activity and obesity, in: Waters, E., Swinburn, B., Seidell, J., Uauy, R. (Eds.), Preventing Childhood Obesity: Evidence, Policy and Practice. Wiley-Blackwell, Chichester.

Whyte, W.H., 1988. City: Rediscovering the Center. Doubleday, New York.

Wilkinson, P., Edwards, P., Steinbach, R., Petticrew, M., Goodman, A., Jones, A., Roberts, H., Kelly, C., Nellthorpe, J., Green, J., 2011. The health impact of free bus travel for young people in London: protocol for an observational study, LSHTM Occasional Papers in Transport and Health. LSHTM, London. 